\title{
Hydrogen storage in MgAlTiFeNi high entropy alloy
}

\author{
K.R. Cardoso ${ }^{\mathrm{a}}$, V. Roche ${ }^{\mathrm{b}}$, A.M. Jorge ${ }^{\mathrm{b}, \mathrm{c}}$, F. J. Antiqueira ${ }^{\mathrm{c}}$, G. Zepon ${ }^{\mathrm{c}}$, Y. Champion \\ aFederal University of São Paulo, ICT, 12231-280 São José dos Campos, SP, Brazil \\ ${ }^{\mathrm{b}}$ Grenoble Alpes University, CNRS, LEPMI, F-38000 Grenoble, France \\ 'Federal University of São Carlos, DEMa, 13565-905, São Carlos, SP, Brazil \\ ${ }^{\mathrm{d}}$ Grenoble Alpes University, CNRS, SIMAP, F-38000 Grenoble, France
}

\begin{abstract}
In this study, the MgAlTiFeNi high entropy alloy was processed by high-energy ball milling under both argon and hydrogen atmospheres. It is shown that this alloy forms a body-centered cubic (BCC) structure when milled under an argon atmosphere (mechanical alloying-MA) and a combination of BCC, FCC, and $\mathrm{Mg}_{2} \mathrm{NiH}_{4}$ when milled under hydrogen pressure (reactive milling-RM). The hydrogen storage behavior of the RM samples was evaluated by a combination of thermal analyses and manometric measurements in a Sieverts apparatus. The RM alloy presented a functional hydrogen storage capacity of $0.94 \mathrm{wt} \%$ and a very high hydrogen absorption and desorption kinetics at temperatures $100{ }^{\circ} \mathrm{C}$ lower than the one for the desorption temperature of the commercial $\mathrm{MgH}_{2}$. Electrochemical discharge of RM samples showed precisely the same hydrogen contend as that obtained in the gas desorption. Electrochemical charging/discharging experiments also were performed in the MA samples, which, however, presented lower electrochemical storage capacity, a behavior probably resulting from the instability of the alloy in the alkaline solution with the formation of a hydroxide layer on its surface that hinders the electrochemical reactions.
\end{abstract}

\section{Introduction}

Metal hydrides are good alternatives for hydrogen storage due to their high gravimetric and volumetric capacity, high absorption/desorption reversibility, safety, and low cost. Many systems have been studied for hydrogen storage applications, especially those based on Mg [1-4]. However, high gravimetric metal hydrides, particularly Mgbased ones, still need high temperatures for hydrogen sorption and have unfavorable absorption and desorption kinetics [2,5]. 
One strategy to overcome these scientific and technological challenges is to explore structurally uncommon materials, dissimilar from those explored so far. High entropy alloys (HEA) are unconventional metallic materials that have at least five major elements and are capable of forming multicomponent solid solutions [6-9]. The lattice distortion of these multicomponent alloys influences their mechanical, physical, and chemical properties.

Although so far, there are few published studies on the functionality of high entropy alloys for hydrogen storage, the number of works regarding HEAs has been increasing, thus demonstrating a great interest in the theme. It has recently been reported that the equiatomic HEA TiVZrNbHf, which crystallizes as a single multicomponent solid solution, is capable of storing 2.5 hydrogen atoms per atom of a metal (H/M). Such a capacity is considerably higher than the maximum capacity of binary hydrides $(\mathrm{H} / \mathrm{M}=2)$ [10]. The TiVZrNbHf alloy features a single-phase body-centered cubic (BCC) structure. During hydrogenation, the initial BCC structure of this HEA transforms into a bodycentered tetragonal structure (BCT) (a distorted FCC structure), which is similar to the structure formed in rare-earth compounds [11,12]. The transformation to a less symmetrical BCT structure may be related to the fact that hydrogen must occupy all tetrahedral sites, but also 50\% of octahedral sites in the alloy to bring it to an $\mathrm{H} / \mathrm{M}$ of 2.5 [10]. This behavior has been reported for other alloy compositions [13,14]. Zlotea et al. [13] reported a two-step phase transition during the hydrogenation of TiZrNbHfTa HEA, BCC $\rightarrow$ BCT $\rightarrow$ FCC. A monohydride was formed in the first hydrogenation step, with hydrogen tending to occupy specific octahedral sites, as demonstrated by the great expansion of the c-axis of the BCT structure. Increasing the hydrogen concentration results in a FCC structure. The authors [13] suggested that the largest lattice distortion $(\delta)$ of TiVZrNbHf, when compared to TiZrNbHfTa, should be related to the preferential occupancy of tetrahedral interstices, leading to a single-step transition during hydrogen absorption. In contrast, smallest value of $\delta$ results in a two-steps reaction, typical of BCC alloys. Nygard et al. [14] studied a series of quaternary and quinary high entropy alloys related to the TiVNb ternary system. The alloys have a BCC structure and form FCC hydrides with $\mathrm{H} / \mathrm{M}$ close to 2 . This study suggests that the valence electrons concentration (VEC) plays a vital role in the destabilization of hydrides, i.e., the initial temperature for the hydrogen desorption of FCC hydrides decreases linearly with this parameter. 
Other multiphase and containing Laves phase high entropy alloys have also been considered to hydrogen absorption [15-18]. Kao et al. [15] showed that high entropy alloys of CoFeMnTi $\mathrm{V}_{\mathrm{y}} \mathrm{Zr}_{\mathrm{z}}$ system with $\mathrm{C} 14$ Laves phase structure could absorb up to 1.6 wt\% hydrogen at room temperature $\left(25{ }^{\circ} \mathrm{C}\right)$. The authors studied the $\mathrm{CoFeMnTi}_{\mathrm{x}} \mathrm{V}_{\mathrm{y}} \mathrm{Zr}_{\mathrm{z}}$ system with a systematic variation of $\mathrm{Ti}, \mathrm{V}$, and $\mathrm{Zr}$ contents. They discussed the effect of composition variation on hydrogen storage capacity, kinetics, and hysteresis of absorption/desorption. According to the authors, the dominant factor in storage capacity was the affinity between alloying elements and hydrogen (hydride formation enthalpies), while in kinetics was the size of interstitial sites associated with lattice constants. In turn, Kunce et al. [16,17] synthesized ZrTiVCrFeNi and TiZrNbMoV alloys by direct laser metal deposition (LENS). After synthesis, the ZrTiVCrFeNi alloy, having a microstructure formed predominantly by the C14 Laves phase, acquired the maximum hydrogen capacity of $1.81 \mathrm{wt} \%$ at 100 bar and $50{ }^{\circ} \mathrm{C}$ after activation at $500{ }^{\circ} \mathrm{C}$ for $2 \mathrm{~h}$. After additional heat treatments at $1000{ }^{\circ} \mathrm{C}$ for $24 \mathrm{~h}$, the maximum hydrogen content decreased to $1.56 \mathrm{wt} \%$ under the same hydrogenation conditions. According to the authors, heat treatment improves the composition homogeneity and results in a more relaxed crystal lattice and, consequently, in less deformation of interstitial sites for hydrogen storage [16]. The authors [17] showed that the hydrogen capacity of TiZrNbMoV alloy strongly depends on the synthesis process and, consequently, on the microstructure and phases present. High laser power resulted in the formation of the BCC phase, while, with low laser power, the alloy exhibited a two-phase structure composed by a solid BCC and an orthorhombic NbTi4 type phase. The multiphase TiZrNbMoV metastable alloy absorbed up to $2.3 \mathrm{wt} \%$ at a hydrogen pressure of 85 bar and $50{ }^{\circ} \mathrm{C}$, in the as processed condition. Absorption capacity was reduced to $1.78 \mathrm{wt} \%$ after additional heat treatment. On the other hand, the alloy with a predominant stable BCC phase absorbed only $0.59 \mathrm{wt} \%$ after synthesis and $0.61 \mathrm{wt} \%$ after additional heat treatment. However, in any case, the equilibrium pressure of the hydrogen desorption was very low.

High entropy alloys containing $\mathrm{Mg}$ consist of an attractive system because $\mathrm{Mg}$ is light, cheap and abundant, and has a high absorption capacity. Zepon et al. [19] had synthesized the MgZrTiFe0.5Co0.5Ni0.5 alloy with BCC structure by high energy ball milling, which undergoes a BCC to FCC phase transition during hydrogenation and absorbed 1.2 wt\% of hydrogen. On the other hand, another study [20] on MgTiVCrFe alloy showed poor hydrogen storage performance. Mg-based alloys were also considered as up-and-coming candidates as hydrogen storage alloys for Ni-MH batteries. Efforts to 
improve the electrochemical properties of Mg-based alloys have been made, including processing control to get amorphization or nanocrystallization that have been regarded as very effective ways for activating Mg-based alloys' electrodes. Mixing Mg-based alloys with some other hydrogen storage alloys or compounds with high catalytic activity or good anti-corrosion capability is another strategy to improve the performance of Mgbased anodes [21].

In order to study the hydrogen storage properties in a high entropy low-density alloy, the equimolar composition MgAlTiFeNi was designed. The alloy in the equimolar composition has high entropy of mixture, a valence electrons concentration (VEC) in the range of values for which the BCC structure is expected [22] and high lattice distortion ( $\delta$, which, according to the literature, may be interesting for hydrogen absorption [15]. This paper reports the results from studies on the gaseous and electrochemical hydrogen storage properties of the MgAlTiFeNi alloy synthesized by high energy ball milling. The electrochemical performance of the HE alloy electrode was also studied.

\section{Experimental Procedure}

The equimolar high entropy alloy MgAlTiFeNi was elaborated by high energy ball milling from pure elements with purity ranging from 98\% to 99.8\% (from Alpha Aesar) in a planetary ball mill (Fritsch Pulverisette P-5), using steel vials and balls. Two different milling procedures were used: i) mechanical alloying - milling in an argon atmosphere for $30 \mathrm{~h}$ at $200 \mathrm{rpm}$ and ball to powder weight ratio of 20:1; ii) reactive milling - milling in a hydrogen atmosphere (3MPa) for $24 \mathrm{~h}$ at $600 \mathrm{rpm}$ and ball to powder weight ratio of $40: 1$.

The alloy powder was characterized by x-ray diffractometry (XRD), performed in a PANalytical - X'Pert Pro MPD diffractometer using $\mathrm{CuK} \alpha$ radiation in the angular scanning interval of $2 \theta$ from $10^{\circ}$ to $90^{\circ}$, a step-scan of $0.033^{\circ}$ and a counting time of $1 \mathrm{~s}$.

Samples after charge/discharge cycle were characterized by scanning electron microscopy (SEM) using a high-resolution ZEISS - FEG Ultra 55 SEM. Samples were simple washed in distilled water after cycling and then dried using a thermal blower.

Simultaneous differential scanning calorimetry (DSC) and thermogravimetry (TG) were used to study hydrogen desorption behavior after gaseous absorption. The DSC and TG analyses were performed using the Netzsch STA 449C Jupiter thermal analyzer. The detection and identification of gases, released from samples over the thermal analysis, 
were performed by a quadrupole mass spectrometer (QMS) AELOS coupled with the thermal analyzer. Assessments were conducted by heating the samples from room temperature to $500{ }^{\circ} \mathrm{C}$ at $10^{\circ} \mathrm{C} / \mathrm{min}$ under constant argon flow.

The alloy obtained by reactive milling, hereafter called MR-MgAlTiFeNi, was submitted to absorption/desorption kinetics tests in a Sievert type equipment. The MRMgAlTiFeNi alloy was initially subjected to a desorption test, which was followed by an absorption/desorption cycle. Hydrogen absorption was performed under the hydrogen pressure of $15 \mathrm{bar}(1.5 \mathrm{MPa})$ for $1 \mathrm{~h}$ at $325^{\circ} \mathrm{C}$, at which temperature the desorption rate is higher as previously indicated by the TG measurement. Thus, desorption was performed under 0.1 bar of $\mathrm{H}_{2}$ also at $325^{\circ} \mathrm{C}$.

The electrochemical hydrogen storage properties were measured in a temperaturecontrolled standard three-electrode cell system, in which the MgAlTiFeNi alloy was the working electrode, a Pt mesh was the counter electrode, and the $\mathrm{Hg} / \mathrm{HgO}$ was used as a reference electrode. The alloy electrode was fabricated by mixing the alloy powder with pure nickel powder in a weight ratio of $1: 3$, resulting in a total mass of $0.4 \mathrm{~g}$. The powder mixture was pressed uniaxially with no binder or other additives under a pressure of 150 MPa. After such procedure, a small pellet of $10 \mathrm{~mm}$ in diameter, and 1.0 to $1.5 \mathrm{~mm}$ consolidated thick was produced. Electrochemical experiments were conducted using a Gamry 600+ Potentiostat using a $6 \mathrm{M}$ potassium hydroxide $(\mathrm{KOH})$ solution with continuous argon flux to avoid solution carbonation. The temperature was kept at the room one using a HUBER MPC microprocessor-controlled thermostat, which circulated water in the double jacketed electrochemical cell.

The samples were initially characterized by potentiodynamic scanning from $-0.6 \mathrm{~V}$ to $-1.2 \mathrm{~V}$ with a scan rate of $0.4 \mathrm{mV} / \mathrm{s}$. Based on the potentiodynamic results, galvanostatic charging for $1 \mathrm{~h}$ was performed at $-50 \mathrm{~mA} / \mathrm{g}$ and $-125 \mathrm{~mA} / \mathrm{g}$, step that was immediately followed by cyclic voltammetry (CV) measurements in a potential range of - 1.36 to 0.5 $\mathrm{V}$ (vs. Hg/HgO electrode) at a scan rate of $10 \mathrm{mV} / \mathrm{s}$. These experiments were performed as a first assessment to estimate the current density and potential values for hydrogen absorption. The conditions for the galvanostatic charge/discharge experiments were defined based on preliminary studies in which the charge current density was varied in the range of 100 to $300 \mathrm{~mA} / \mathrm{g}$ and from 20 to $100 \mathrm{~mA} / \mathrm{g}$ for discharge current density. The best combination of current densities that gave rise to the highest discharge capacity was - $200 \mathrm{~mA} / \mathrm{g}$ in the charging step and $20 \mathrm{~mA} / \mathrm{g}$ during the discharging. The working 
electrodes were charged using the galvanostatic mode for $15 \mathrm{~h}$ followed by galvanostatic discharge to a cut-off potential of $0 \mathrm{~V}$ vs. $\mathrm{Hg} / \mathrm{HgO}$.

Experiments were performed to study the electrochemical kinetic properties of the alloys and obtain the hydrogen diffusion coefficient in the bulk of the alloy (D), the exchange current density $\left(\mathrm{I}_{0}\right)$ and the charge transfer resistance $\left(\mathrm{R}_{\mathrm{ct}}\right)$ at the surface layer of the alloy. The hydrogen diffusion coefficient was estimated by the potential-step discharge method, during which the full-charged alloy electrode was discharged at an over potential of $+0.6 \mathrm{~V}$ (vs. OCP) for $10800 \mathrm{~s}$ with the anodic current response recorded versus time. Linear polarization and impedance electrochemical spectroscopy (IES) were performed to obtain the exchange current, and charge transfer resistance, respectively. These last measurements were done in the MA-MgAlTiFeNi electrode in the uncharged condition, fully charged, and in partial (40\%) and total (100\%) discharged state. The linear polarization was performed in a small overpotential range $\pm 5 \mathrm{mV}$ vs. equilibrium potential (OCP) at a scan rate of $0.1 \mathrm{mV} / \mathrm{s}$. The EIS measurements were performed in the frequency range of $10^{5} \mathrm{~Hz}$ to $0.02 \mathrm{~Hz}$, using an amplitude of $5 \mathrm{mV}$ (vs. OCP). These experimental parameters, used in the study the electrochemical kinetic properties, were chosen based on literature data [23-27].

\section{Results and Discussion}

\subsection{Structural characterization of reactive milled samples}

Figure 1 compares X-ray diffraction (XRD) patterns of the MgAlTiFeNi alloy after reactive milling (RM) under a hydrogen atmosphere and after mechanical alloying (MA) under argon atmosphere. Three phases can be identified in the XRD patterns of the RM sample, the main BCC-B2 ordered phase with a lattice parameter of $0.292 \mathrm{~nm}$, a small amount of an FCC phase with a lattice parameter of $0.448 \mathrm{~nm}$, and a small amount of the hydride phase $\mathrm{Mg}_{2} \mathrm{NiH}_{4}$. Milling in argon atmosphere resulted only in the formation of the single BCC-B2 phase with a similar lattice parameter $0.295 \mathrm{~nm}$.

\subsection{Thermal analysis of the reactive milled samples}

Hydride formation during the reactive milling was confirmed by thermal analysis (DSC/TG) coupled to a mass spectrometer (QMS). Figure 2a presents a DSC scan where the hydrogen desorption peak can be observed at around $326{ }^{\circ} \mathrm{C}$. Although reactive milling results in only partial hydrogenation of the alloy, it is interesting to note that the 
peak temperature $\left(326^{\circ} \mathrm{C}\right.$ ) and the onset temperature of $286^{\circ} \mathrm{C}$ for hydrogen desorption are lower than those for commercial magnesium hydride $\left(\mathrm{MgH}_{2}\right)$ which are roughly on average $426{ }^{\circ} \mathrm{C}$ and $442{ }^{\circ} \mathrm{C}$, respectively [28-36]. Figure $2 \mathrm{~b}$ displays the TG curve from which one obtained the value of $0.87 \mathrm{wt} \%$ of hydrogen absorbed in the alloy by reactive milling.



Figure 1. XRD pattern of MgAlTiFeNi alloy after reactive milling in a hydrogen atmosphere for $24 \mathrm{~h}$, and after mechanical alloying (MA) under argon atmosphere.

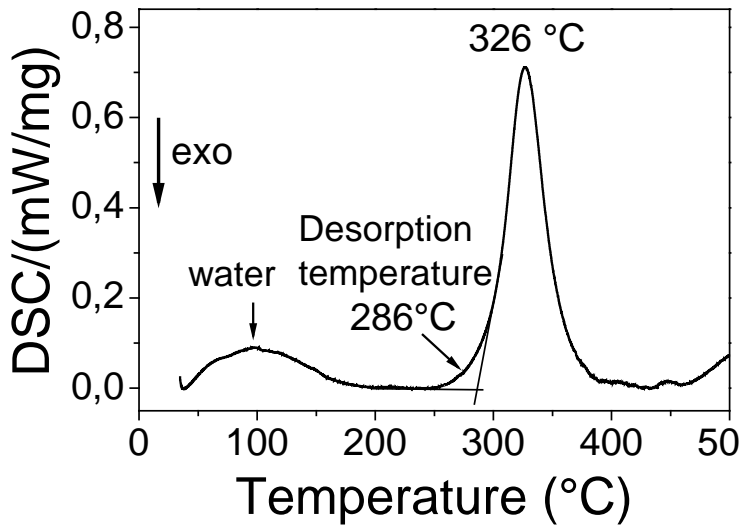

(a)

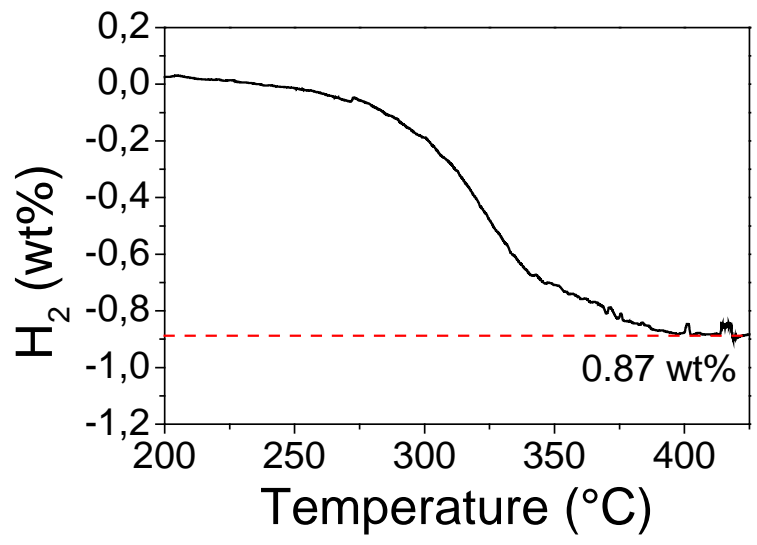

(b)

Figure 2. (a) DSC thermal analysis of partially hydrogenated MgAlTiFeNi alloy obtained by reactive milling, (b) thermogravimetric analysis of partially hydrogenated MgAlTiFeNi alloy obtained by reactive milling. 


\subsection{Kinetics of gaseous hydrogen absorption/desorption}

As stated in the methodology, the partially hydrogenated alloy obtained by reactive milling (RM-MgAlTiFeNi) was subjected to absorption/desorption kinetics tests in a Sievert type equipment. The sample was initially submitted to desorption, which was followed by an absorption/desorption cycle. Figure 3 presents the first desorption curve, obtained directly from the as milled powder. The hydrogen desorption kinetics of the RMMgAlTiFeNi alloy is very high, 93\% of the acquired capacity of hydrogen (0.81wt.\%) occurred in less than $50 \mathrm{~s}$. Figure 4 presents curves of hydrogen absorption and desorption of the reactive milled sample performed after its first desorption. The amount of hydrogen absorbed in this cycle increased to about 1 wt.\% (Fig. 4a), and the desorption kinetics remained quite high, with 100\% hydrogen being desorbed in less than $100 \mathrm{~s}$ (Figure 4b).

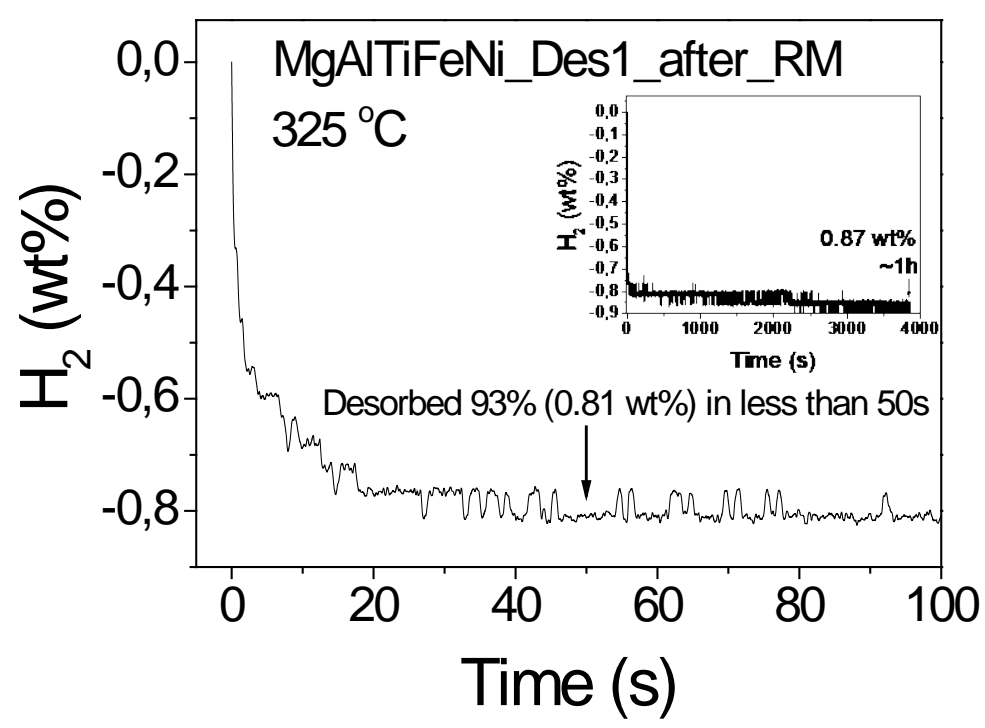

Figure 3. Hydrogen desorption at $325{ }^{\circ} \mathrm{C}$ for partially hydrogenated MgAlTiFeNi alloy produced by reactive milling. 


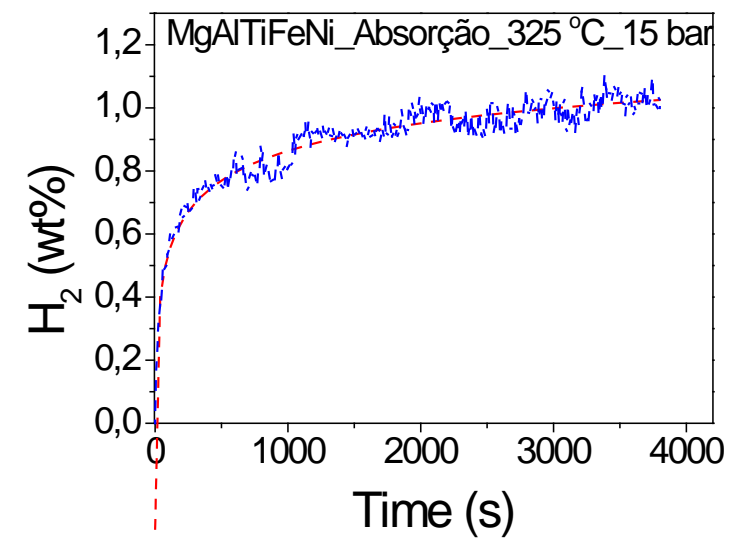

(a)

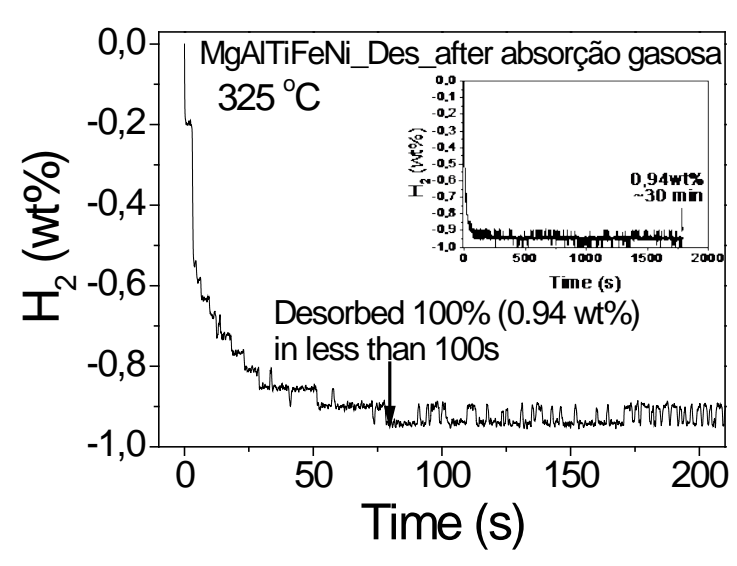

(b)

Figure 4. (a) Hydrogen absorption curve performed on Sievert-type equipment at $325^{\circ} \mathrm{C}$ under 15 bar of hydrogen pressure, (b) Hydrogen desorption at $325^{\circ} \mathrm{C}$ for MgAlTiFeNi alloy after gas absorption.

Figure 5 shows a comparison of the XRD patterns obtained from the alloy after reactive milling and after the second desorption. The hydride-related peaks vanished after the desorption step, indicating that the sample was wholly desorbed. However, the peaks of the FCC phase are still present in the XRD diffractogram after desorption.

It has been reported by some authors $[10,19]$ that some high entropy alloys with BCC structure undergo a phase transformation to FCC when absorbing hydrogen. The formation of FCC hydride directly during reactive milling of a HEA has been recently reported [19]. In the present work, the alloy was mechanically activated to improve hydrogen absorption that resulted in the formation of the complex hydride $\mathrm{Mg}_{2} \mathrm{NiH}_{4}$ phase and a FCC phase. As the milling in the argon atmosphere resulted only in a BCC solid solution phase, the first assumption would be that the FCC phase was also related to the hydride formation. However, as observed by XRD patterns of Figure 5, the peaks of the FCC phase remain after desorption, indicating that this phase is not related to hydride formation, but with the milling conditions. The reactive milling conditions were more energetic than the ones used to mill in an argon atmosphere. Therefore, one may infer that the mechanically activated MgAlTiFeNi alloy does not have the same hydrogen sorption behavior as the high entropy alloys reported heretofore in the literature $[10,13,14,19]$.

The good hydrogen capacity stored in only one hour of testing at $325{ }^{\circ} \mathrm{C}$, at a low hydrogen pressure, and the high absorption and desorption kinetics are promising results for applications of the MgAlTiFeNi high entropy alloy for hydrogen storage. Partial 
hydride formation during reactive milling and increased capacity in the second absorption/desorption cycle indicate that adjustments in the process and milling parameters can further improve these results. Furthermore, the MgAlTiFeNi alloy has advantages over other high entropy alloys evaluated so far for hydrogen application [1318], such as the relatively low cost of the constituent elements and low density (4.4 $\mathrm{g} / \mathrm{cm} 3)$, which are also essential factors for the application of these alloys in hydrogen storage systems.

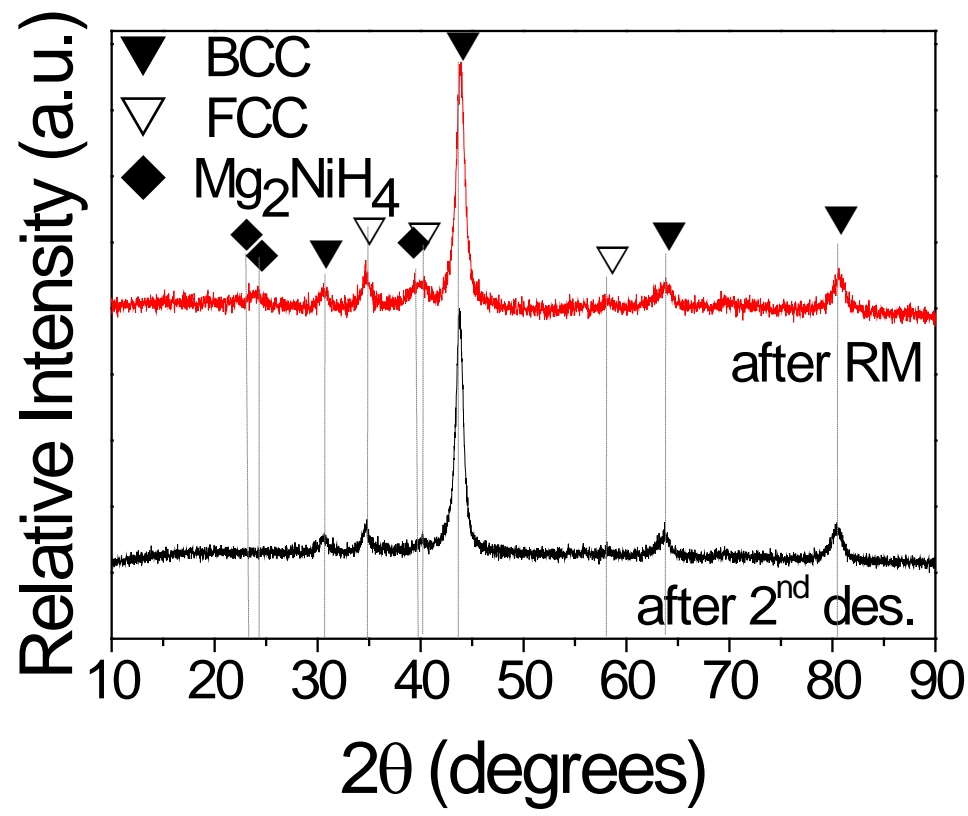

Figure 5. XRD patterns of MgAlTiFeNi alloy subjected to reactive milling in a hydrogen atmosphere and after desorption.

\subsection{Electrochemical hydrogen absorption/desorption behaviors}

The search for more efficient and clean vehicles, as the petrol-electric hybrids and battery electric ones $[37,38]$, has driven research on hydrogen absorption materials for electrochemical hydrogen storage [21,39]. The electrochemical hydrogen properties of MgAlTiFeNi HE alloy elaborated by mechanical alloying and reactive milling were analyzed.

The sample obtained by reactive milling was electrochemically discharged in galvanostatic and potentiostatic mode for comparison with the values obtained in the gas desorption and to validate the electrochemical method. Figure 6a shows the galvanostatic discharge curve of this sample performed with a specific current density of $20 \mathrm{~mA} / \mathrm{g}$, which resulted in a discharge capacity of $340 \mathrm{mAh} / \mathrm{g}$. 
The theoretical electrochemical hydrogen storage capacity of an alloy is determined by the $\mathrm{H}$ capacity in the plateau of the pressure-composition-isothermal (PCI) curve. It can be calculated from equation 1 , where $\mathrm{F}, \mathrm{C}_{\mathrm{H}}$, and $\mathrm{M}_{\mathrm{W}}$ represent the Faraday constant, atoms per formula unit (H/f.u.), and the molecular weight of the alloy in g/f.u., respectively [21].

$$
C_{H}=\frac{3.6 \times M_{W}}{F} C(m A h / g)
$$

By using equation (1), the hydrogen amount could be estimated as $1.27 \mathrm{wt} \%$ for galvanostatic discharge, a value slightly higher than that obtained by the gaseous desorption measurement. Figure $6 \mathrm{~b}$ shows the potentiostatic discharge graph obtained at a potential $\mathrm{V}=-0.915 \mathrm{~V}$ (vs. $\mathrm{Hg} / \mathrm{HgO}$ ). The discharge was performed at a potential slightly higher than the OCP to minimize the hydroxide layer formation over the sample surface that hinders the hydrogen release process. The measured capacity using this kind of discharge was $257 \mathrm{mAh} / \mathrm{g}$, giving an equivalent mass of $0.96 \mathrm{wt} \%$ of hydrogen, which is the same value as that obtained by gas desorption. The greater capacity obtained by the galvanostatic method may be result of the occurrence of other forced reactions imposed to the system so that the demanded current can be kept constant.



(a)

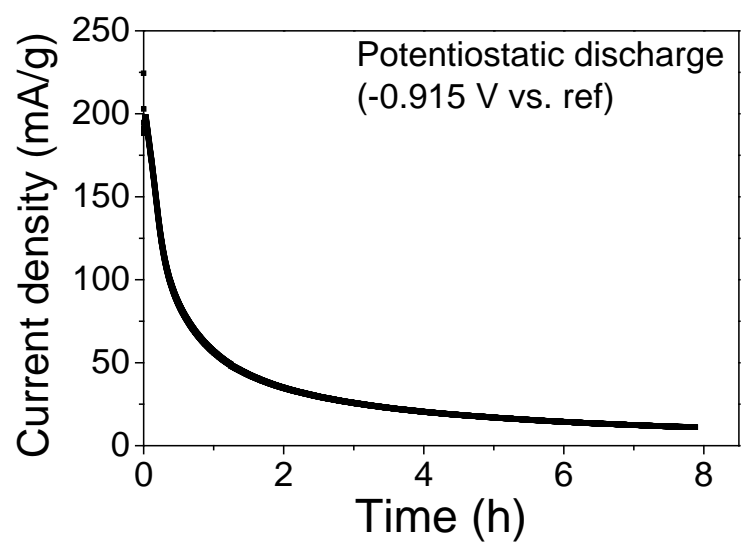

(b)

Figure 6. Discharge curves for RM-MgAlTiFeNi electrodes. (a) Galvanostatic discharge obtained with a specific current density of $20 \mathrm{~mA} / \mathrm{g}$. (b) Potentiostatic discharge at $\mathrm{V}=$ $0.915 \mathrm{~V}$ (vs. Hg/HgO). 
The electrochemical charge capacity of the mechanically alloyed powder (MAMgAlTiFeNi) was evaluated by galvanostatic charging and galvanostatic and potentiostatic discharging measurements. As described in the experimental procedures, galvanostatic charge/discharge experiments, at different current densities, were carried out to evaluate the effects on discharge capacity. Also, preliminary potentiodynamic scanning and cyclic voltammetry (VC) were performed to help find the current density for hydrogen absorption.

During the time the sample is subjected to cathodic polarization, i.e., during the charging step, the Volmer reaction (equation 2) and the absorption of hydrogen (equation 3) take place. The hydrogen adsorbed on the sample surface diffuses into the crystal structure to form the hydride $[40,41]$.

$$
\begin{aligned}
& \mathrm{H}_{2} \mathrm{O}+\mathrm{M}+\mathrm{e}^{-} \longrightarrow \mathrm{MH}_{\mathrm{ads}}+\mathrm{OH}^{-} \text {(Volmer reaction) } \\
& \mathrm{MH}_{\mathrm{ads}} \longrightarrow \mathrm{MH}_{\mathrm{abs}} \text { (absorption) }
\end{aligned}
$$

Figure 7a shows the current density plot as a function of the potential obtained in the potentiodynamic test on the MA-MgAlTiFeNi electrode. The cathodic branch of the curve shows a diffusion plateau, in which the current density is approximately constant, preceding the beginning of the hydrogen release reaction. The limiting diffusion current density ends with a potential in which the evolution of hydrogen becomes predominant. Short time galvanostatic charging tests $(60 \mathrm{~min})$ were performed at specific current densities greater than this limit, - $50 \mathrm{~mA} / \mathrm{g}$ and - $125 \mathrm{~mA} / \mathrm{g}$. After the charging step, the working electrodes were submitted to cyclic voltammetry tests, which curves are presented in Figure 7b. It can be seen from Figure 7b that as the charging current density increases from $-50 \mathrm{~mA} / \mathrm{g}$ to $-125 \mathrm{~mA} / \mathrm{g}$, the anodic current density of the hydrogen reoxidation peak increases, and the peak slightly shifts in the anodic direction. The rise in the peak current density indicates an increase in the number of species to be oxidized, while the shift to more anodic values shows a necessary increase in energy to favor hydrogen diffusion. These results confirm the adsorption and absorption of hydrogen (equation 2 and 3) by the sample in the cathodic polarization experiment (charging step) and show that increasing the charging current density, favors the hydrogen absorption. 


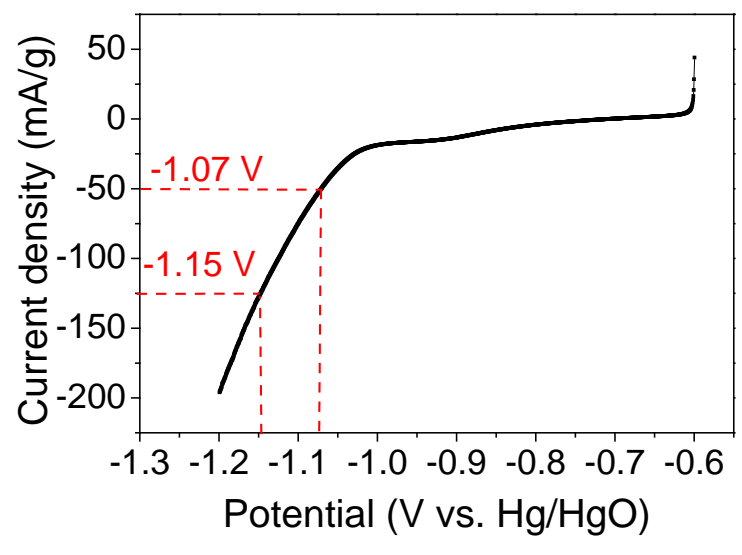

(a)

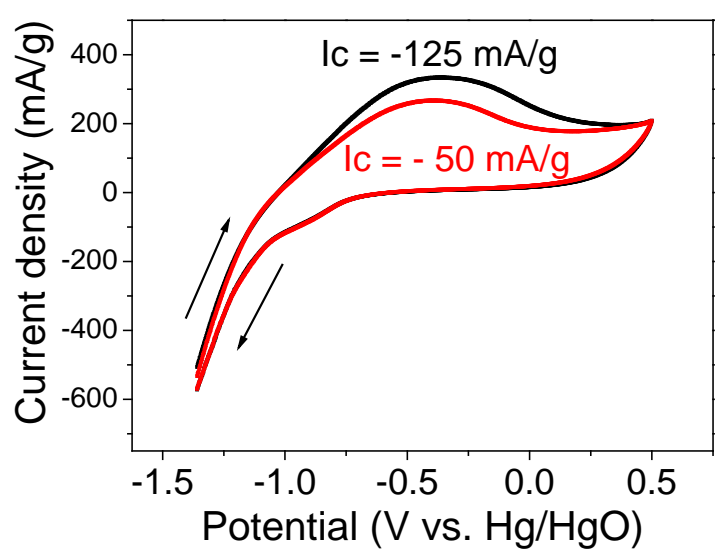

(b)

Figure 7. (a) Current density curve as a function of the potential obtained from the MAMgAlTiFeNi electrode in a potentiodynamic sweep from $-0.6 \mathrm{~V}$ to $-1.2 \mathrm{~V}$ with a scan rate of $0.4 \mathrm{mV} / \mathrm{s}$. (b) Voltammograms, obtained with a scan rate of $10 \mathrm{mV} / \mathrm{s}$ in a potential range of - 1.36 to $0.5 \mathrm{~V}$ (vs. $\mathrm{Hg} / \mathrm{HgO}$ electrode), after 1 hour of galvanostatic charging with current densities - $50 \mathrm{~mA} / \mathrm{g}$ and $-125 \mathrm{~mA} / \mathrm{g}$. Experiments were performed in a $6 \mathrm{M}$ $\mathrm{KOH}$ solution at $25^{\circ} \mathrm{C}$.

Considering the last results, and other previous experiments concerning the effects of charging and discharging current densities on discharge capacity, the MAMgAlTiFeNi electrode was submitted to a charging step of $15 \mathrm{~h}$ with a specific current density equal to $-200 \mathrm{~mA} / \mathrm{g}$, followed by the galvanostatic discharge with a specific current density of $20 \mathrm{~mA} / \mathrm{g}$. As presented in Figure 8a, the galvanostatic discharge of the MA-MgAlTiFeNi electrode resulted in a discharge capacity of $145 \mathrm{mAh} / \mathrm{g}$ or the equivalent to $0.54 \mathrm{wt} \%$ of hydrogen a value quite lower than that obtained in the discharging of RM-MgAlTiFeNi.

Potentiostatic discharge was also used after a galvanostatic charging step performed in the same conditions described in the previous paragraph. The discharge was performed at an overpotential of $+0.6 \mathrm{~V}$ (vs. OCP), a condition chosen based on data from the literature, the same used to study the electrochemical kinetic properties [26,27]. The resulting curve of this discharge is presented in Figure 8b. The discharging capacity obtained by integrating the curve was $103 \mathrm{mAh} / \mathrm{g}$, which is lower than that obtained in the galvanostatic discharge tests $(145 \mathrm{mAh} / \mathrm{g})$. This difference was already discussed in this text and should be related to additional forced reactions in the galvanostatic method. 
Finally, the above results indicate that either a pre-activation of the alloy or different crystalline structures obtained by reactive milling are conditions possibly necessary for both gaseous and electrochemical hydrogenation properties.

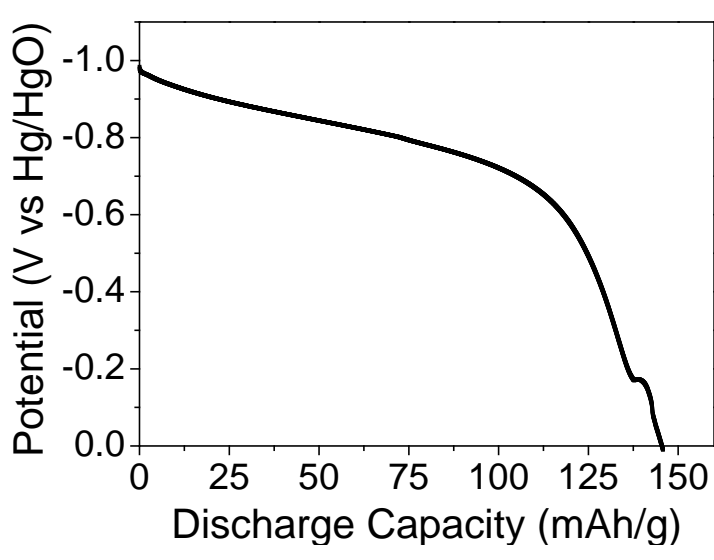

(a)

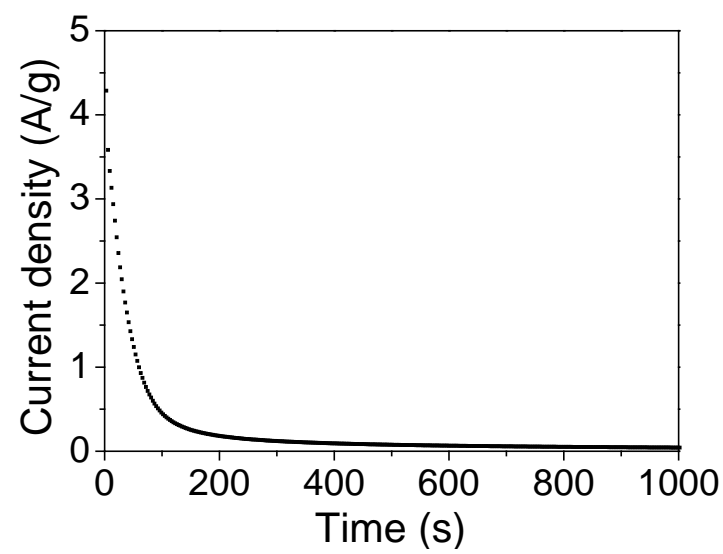

(b)

Figura 8. Discharges curves of MA-MgAlTiFeNi electrode after a galvanostatic charging step at I = - $200 \mathrm{~mA} / \mathrm{g}$ for $15 \mathrm{~h}$. (a) Galvanostatic discharge at $20 \mathrm{~mA} / \mathrm{g}$; (b) Potentiostatic discharge at an overpotential of $+0.6 \mathrm{~V}$ (vs OCP) Experiments were performed in a $6 \mathrm{M}$ $\mathrm{KOH}$ solution at $25^{\circ} \mathrm{C}$.

\subsection{Corrosion properties}

Figure 9 presents Nyquist plots (Figs. 9a and 9b) resulted from electrochemical impedance spectroscopy tests (EIS) on surfaces of electrodes MA-MgAlTiFeNi, in the as-cold-pressed condition (uncharged), after full galvanostatic charging and after partial (40\%) and total (100\%) galvanostatic discharges. The Bode magnitude plot (log modulus versus $\log$ f) is presented in Figure 9c. Also, a SEM image of the sample surface after discharge is presented (Fig. 9d).

The Nyquist plots of all those conditions are presented in Figure 9a. Overall, all of them are very similar to those reported in the literature for the considered electrolyte $[27,42-44]$. The graphs show two semicircles, one with a small radius at high frequencies and one with a variable radius at a medium frequency (Fig. 9b). At low frequency, a linear behavior is commonly observed, except in the as cold-pressed sample. The small semicircle found at high frequencies has been associated in the literature with interfacial contact impedance between alloy particles and conductive material [27,42,44]. It can be modeled by a parallel resistance and capacitance. These impedance values vary very little 
in this study, as shown in Figure 9b, and it is, therefore, reasonable to associate it with the contact between alloy particles and conductive material. The larger semicircle in the mid-frequency region is associated with the load transfer resistance and the double-layer capacitance of the alloy surface and, therefore, can also be modeled as a parallel resistance and capacitance. The line observed in the low-frequency region has been associated with the semi-infinite diffusion of hydrogen within the alloy and can be modeled by a Warburg element [42-44].

The Bode magnitude plot (Fig. 9c) clearly show that after the charging step, the modulus at lowest frequency is reduced, indicating an impedance decrease, behavior that results from the reduction of the pre-existing oxide layer on the sample surface during cathodic polarization. On the other hand, during discharging, the anodic polarization results in the formation of a metal hydroxide layer on the sample surface, thus increasing the impedance. This behavior is more pronounced in the fully discharged sample, as shown by the marked increase in the modulus, Figure 9c.

The two circuit models used in this work are presented in Figure 10. Model 1 was used in modeling the sample before electrochemical charging, a condition in which there is no hydrogen absorbed inside the alloy. Model 2 was used for the other samples.

The kinetics of electrochemical reactions is controlled by the charge transfer rate on the interface electrode/electrolyte and by the diffusivity of hydrogen in the electrode depending on the frequency range [21,45]. Charge transfer processes can be characterized by charge transfer resistance $\left(\mathrm{R}_{\mathrm{ct}}\right)$ and exchange current density $\left(\mathrm{I}_{0}\right)$, while diffusivity can be evaluated by the hydrogen diffusion coefficient (D) [21, 46,47].

The charge transfer resistance $\left(\mathrm{R}_{\mathrm{ct}}\right)$ is obtained from electrochemical impedance spectroscopy modeling of electrochemical reactions using equivalent circuits. The exchange current density $\left(\mathrm{I}_{0}\right)$ is a critical kinetic parameter that measures the electrode's ability to supply current at high rates and can be calculated from equation 4 [21,43]:

$$
I_{0}=\frac{R T}{R_{c t} F}
$$

where $\mathrm{R}, \mathrm{T}$, and $\mathrm{F}$ denote the gas constant, the absolute temperature, and the Faraday constant, respectively. 


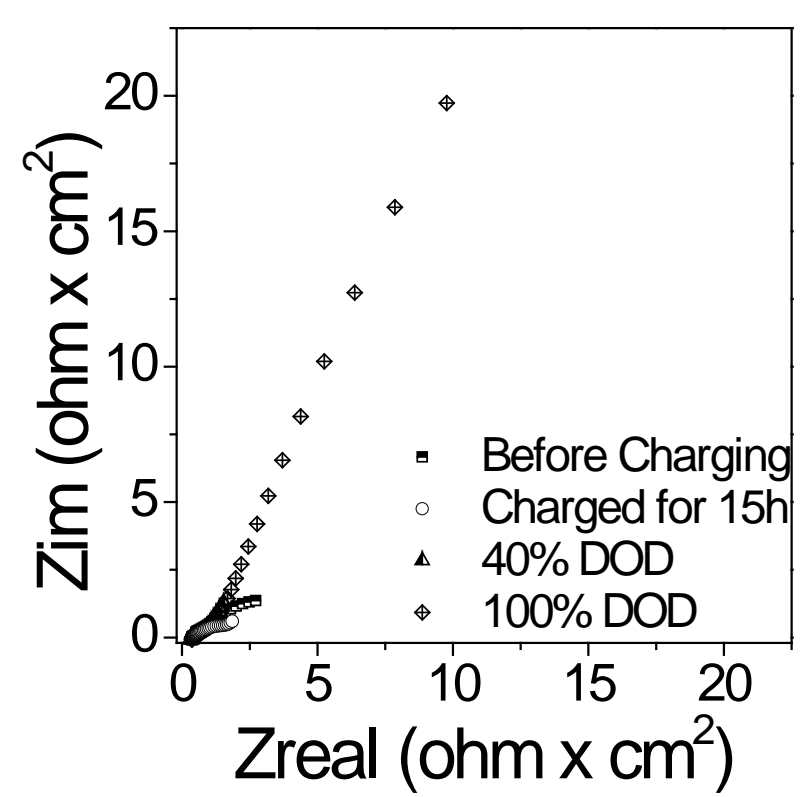

(a)



(c)

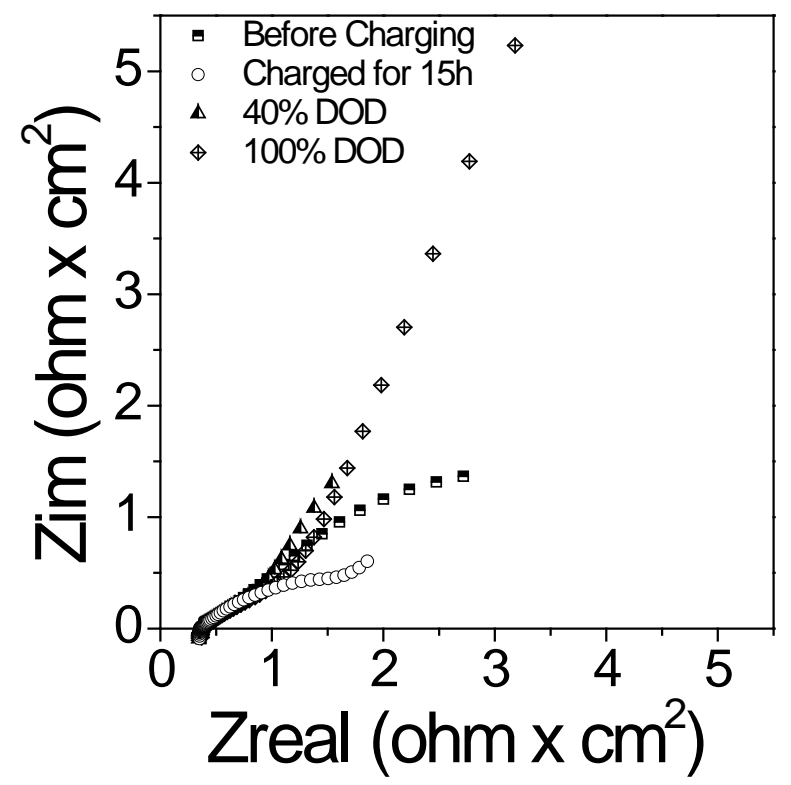

(b)

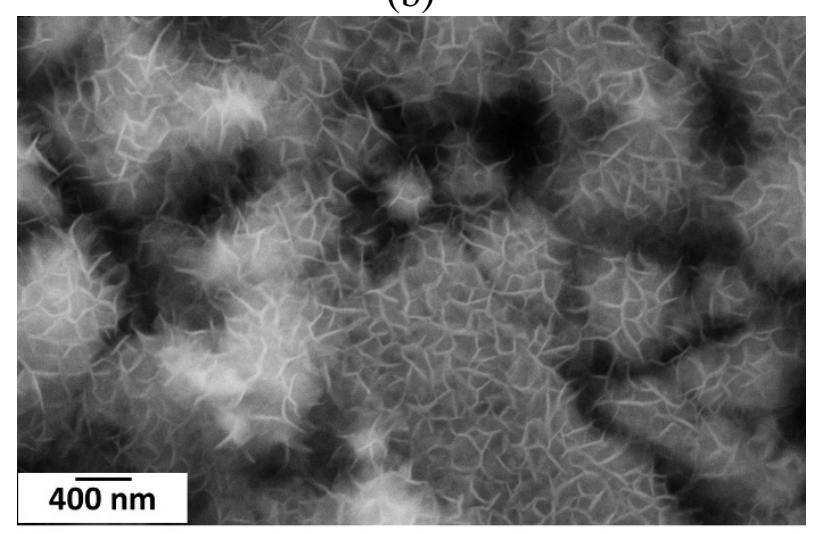

(d)

Figure 9. (a) IES curves obtained from electrodes composed of Ni powder and coldpressed MA-MgAlTiFeNi alloy powder. The assays were performed before electrochemical charging, in the fully charged sample and after partial (40\%) and total (100\%) galvanostatic discharges. (b) Magnification of the high-frequency region of all IES curves. (c) Bode magnitude plot (log modulus versus $\log$ f). (d) SEM micrograph of MA-MgAlTiFeNi alloy surface after anodic polarization. Experiments were performed in a $6 \mathrm{M} \mathrm{KOH}$ solution at $25^{\circ} \mathrm{C}$. 
1
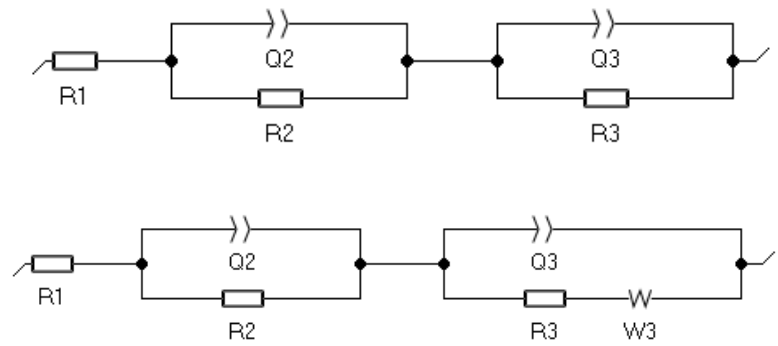

Figure 10. Equivalent circuits used to model EIS results.

$R_{\mathrm{ct}}$ was obtained from the fitting of IES spectra of MA-MgAlTiFeNi electrode in the uncharged condition, in the fully charged state ( $\mathrm{I}=-200 \mathrm{~mA} / \mathrm{g}$ for $15 \mathrm{~h}$ ), and after partial (40\%) and total (100\%) discharge. The values of charge transfer resistances are presented in Table 1 . The data show a reduction in $\mathrm{R}_{\mathrm{ct}}$ after electrochemical charge and a sharp increase in $\mathrm{R}_{\mathrm{ct}}$ after discharge, a result that comes, as already pointed out, from the formation of a metal hydroxide layer on the sample surface (Fig. 9d). The exchange current density for the MA-MgAlTiFeNi electrode in the same conditions is also presented in Table 1. The highest exchange current density was obtained for the partially discharged electrode, a value that was considerably reduced in the fully discharged state. As previously stated, $\mathrm{R}_{\mathrm{ct}}$ and the $\mathrm{I}_{0}$ are parameters that define the charge transfer rate that must be high enough to ensure a high rate dischargeability (HRD), avoiding a delay in the charging or discharging processes, and a reduction in the electrochemical properties. The values of $R_{c t}$ and the $I_{0}$ found in the MA-MgAlTiFeNi electrode in the as fully charged condition, are good enough to ensure a high HRD. Although, the anodic polarization during the electrode discharge process significantly increases the $R_{c t}$ and consequently decreases $\mathrm{I}_{0}$. It is believed that the metal hydroxide layer acts as a barrier for the atomic hydrogen in and out-diffusion and deteriorates the electrode's cyclability $[48,49]$.

Table 1. Charge transfer resistance, exchange current density, and diffusion coefficient calculated from electrochemical tests.

\begin{tabular}{|c|c|c|c|c|}
\hline MA-MgAlTiFeNi & $\begin{array}{c}\mathbf{R}_{\mathrm{TC}} \\
\left(\mathbf{\Omega . c m}^{2}\right)\end{array}$ & $\begin{array}{c}\mathbf{I}_{0} \\
\left(\mathrm{~mA} \cdot \mathrm{cm}^{-2}\right)\end{array}$ & $\begin{array}{c}\mathrm{I}_{0} \\
(\mathrm{~mA} / \mathrm{g})\end{array}$ & $\begin{array}{c}\mathrm{D} \\
\left(\mathrm{cm}^{2} / \mathrm{s}\right)\end{array}$ \\
\hline Cold pressed & 4.6 & 5.6 & 44.5 & $0.18 \times 10^{-10}$ \\
\hline As-charged -15 h & 0.9 & 28.4 & 215.3 & - \\
\hline 40\% discharge & 2.9 & 9.0 & 71.8 & - \\
\hline 100\% discharge & 218.5 & 0.11 & 0.9 & - \\
\hline
\end{tabular}


The hydrogen diffusion coefficient, D ( $\left.\mathrm{cm}^{2} / \mathrm{s}\right)$, another critical and limiting kinetic parameter of the electrode reaction rate, can be obtained by potentiostatic discharge methods (potential-step methods). According to Zheng et al. [50], D can be estimated from the slope of the linear portion of the obtained curves, according to equations 5 and 6 ,

$$
\begin{gathered}
\log (i)=\log \left[ \pm \frac{6 F D}{d a^{2}}\left(C_{0}-C_{S}\right)\right]-\left(\frac{\pi^{2}}{2.303}\right)\left(\frac{D}{a^{2}}\right) t \\
D=-2.303 \frac{a^{2}}{\pi^{2}}\left(\frac{d \log (i)}{d t}\right)
\end{gathered}
$$

where $\mathrm{i}(\mathrm{A} / \mathrm{g})$ is the diffusion current density, $\mathrm{C}_{0}\left(\mathrm{~mol} / \mathrm{cm}^{3}\right)$ is the initial concentration of hydrogen in the alloy, $\mathrm{C}_{\mathrm{s}}\left(\mathrm{mol} / \mathrm{cm}^{3}\right)$ is the concentration of hydrogen on the surface of the alloy particles, a $(\mathrm{cm})$ is the particle radius, $\mathrm{d}\left(\mathrm{g} / \mathrm{cm}^{3}\right)$ is the density of hydrogen stored in the alloy and $\mathrm{t}$ (s) is the discharge time. The hydrogen coefficient diffusion was estimated for the MA-MgAlTiFeNi alloys considering an average particle radius of 12 $\mu \mathrm{m}$ in the fully charged condition (after a galvanostatic charging step at -200 mA/g for $15 \mathrm{~h}$ ). The estimated result for $\mathrm{D}$ is shown in Table 1 . The value found for the MAMgAlTiFeNi alloy is very close to that observed for some representative hydrogen storage alloys, reported by Ouyang et al. in their review [21].

\section{Conclusions}

The high entropy MgAlTiFeNi alloy, with a BCC phase, was successfully produced by high energy ball milling. The alloy presented a functional hydrogen storage capacity of 0.94 wt\% after activation obtained during reactive milling (RM-MgAlTiFeNi).

Very high hydrogen absorption and desorption kinetics were observed in reactive milled samples (RM-MgAlTiFeNi alloy), from which hydrogen was practically wholly desorbed in a few seconds, at temperatures $100{ }^{\circ} \mathrm{C}$ lower than the one for the desorption temperature of the commercial $\mathrm{MgH}_{2}$. The results obtained so far show that the alloy has reversibility and good potential for hydrogen storage applications.

The RM-MgAlTiFeNi alloy was also submitted to electrochemical discharge for comparison with the value obtained in the gas desorption and for validation of the electrochemical method. The hydrogen content received by the potentiostatic discharge was precisely the same as that obtained in the gas desorption. 
Electrochemical charging/discharging experiments also were performed in the alloy elaborated by mechanical alloying. The highest capacity obtained in electrochemical charging was $145 \mathrm{mAh} / \mathrm{g}$ (in galvanostatic discharge mode) and $103 \mathrm{mAh} / \mathrm{g}$ (in potentiostatic discharge mode). The values of the kinetics parameters that control the electrochemical reactions show high reaction rates at the beginning of the discharge, which is, however, impaired by the formation of the hydroxide film on the electrode surface. These results seem to indicate that improving the stability of the alloy in an alkaline solution is a great challenge to be faced.

\section{Acknowledgments}

The authors would like to thank the Brazilian funding agency FAPESP for financial support (research grant - 2018/09548-2), the Science et Ingénierie des Matériaux et Procédés Laboratory, INP - Grenoble, the Laboratoire d'Electrochimie et de Physicochimie des Matériaux et des Interfaces, INP - Grenoble, and the Laboratory of Hydrogen in Metals (LHM) at the Department of Materials Engineering of the Federal University of São Carlos.

\section{References}

[1] Schlapbach L, Zuttel A. Hydrogen-storage materials for mobile applications. Nature 414 (2001) 353-358. https://doi.org/10.1038/35104634

[2] Sakintuna B, Darkrim FL, Hirscher M. Metal hydride materials for solid hydrogen storage: A review. Int J Hydrogen Energy. v. 32(9) (2007) 1121-1140. https://doi.org/10.1016/j.ijhydene.2006.11.022

[3] Sandrock G. A panoramic overview of hydrogen storage alloys from a gas reaction point of view. J Alloys Compd., v. 293-295 (1999), 877-888. https://doi.org/10.1016/S0925-8388(99)00384-9

[4] Zaluska A, Zaluski L, Ström-Olsen JO. Synergy of hydrogen sorption in ball-milled hydrides of $\mathrm{Mg}$ and $\mathrm{Mg}_{2} \mathrm{Ni} . \quad \mathrm{J}$ Alloys Compd., v. 289 (1999)197-206. https://doi.org/10.1016/S0166-0462(99)00013-7

[5] Zuttel A. Materials for hydrogen storage. Materials Today, v. 6 (9) (2003) 24-33. https://doi.org/10.1016/S1369-7021(03)00922-2 
[6] Zhang Y, Zuo TT, Tang Z, Gao MC, Dahmen KA, Liaw PK, Lu ZP. Microstructures and properties of high-entropy Alloys. Progress in Materials Science. 61 (2014)1-93. https://doi.org/10.1016/j.pmatsci.2013.10.001

[7] Ye YF, Wang Q, Lu J, Liu CT, Yang Y. High-entropy alloy: challenges and prospects.

Materials Today, $\quad$ Vol $\quad 19-6 \quad$ 349-362. https://doi.org/10.1016/j.mattod.2015.11.026

[8] Miracle DB, Senkov ON. A critical review of high entropy alloys and related concepts. Acta Materialia 122 (2017) 448-511. https://doi.org/10.1016/j.actamat.2016.08.081

[9] Gao MC, Miracle DB, Maurice D, Yan X, Zhang Y, Hawk JA. High-entropy functional materials. Journal Materials Research, 33, $n^{\circ} 19$ (2018) 3138-3155. https://doi.org/10.1557/jmr.2018.323

[10] Sahlberg M, Karlsson D, Zlotea C, Jansson U. Superior hydrogen storage in high entropy alloys. Sci Rep 6 (2016) 36770. https://doi.org/10.1038/srep36770

[11] Knappe P, Müller H, Mayer HW. Tetragonal rare earth hydrides REH(D) 2.33 (RE $=\mathrm{La}, \mathrm{Ce}, \mathrm{Pr}, \mathrm{Nd}, \mathrm{Sm}$ ) and a neutron diffraction study of NdD2.36. J. Less-Common Met. 95(2) (1983) 323-333. https://doi.org/10.1016/0022-5088(83)90527-1

[12] Holley CE et al. The Crystal Structure of Some Rare Earth Hydrides. J. Phys. Chem. 59(12) (1955) 1226-1228. https://doi.org/10.1021/j150534a010

[13] Zlotea C, Sow MA, Ek G, Couzini J-P, Perrière L, Guillot I, Bourgon J, Møller KT, Jensen TR, Akiba E, Sahlberg M. Hydrogen sorption in TiZrNbHfTa high entropy alloy. Journal of Alloys and Compounds 775 (2019) 667-674. https://doi.org/10.1016/j.jallcom.2018.10.108

[14] Nygård MM, Ek G, Karlsson D, Sørby MH, Sahlberg M, Hauback BC. Counting electrons - A new approach to tailor the hydrogen sorption properties of high-entropy $\begin{array}{lllll}\text { alloys. } & \text { Acta } & \text { Materialia } & 175 & \text { (2019) }\end{array}$ https://doi.org/10.1016/j.actamat.2019.06.002

[15] Kao YF, Chen SK, Sheu JH, Lin JT, Lin WE, Yeh JW, et al. Hydrogen storage properties of multi-principal-component CoFeMnTixVyZrz alloys. Int J Hydrogen Energy, v.35 (2010) 9046-9059. https://doi.org/10.1016/j.ijhydene.2010.06.012

[16] Kunce I, Polanski M, Bystrzycki J. Structure and hydrogen storage properties of a high entropy ZrTiVCrFeNi alloy synthesized using Laser Engineered Net Shaping (LENS). Int J Hydrogen Energy, v. $38 \quad$ (2013) 12180-12188. http://dx.doi.org/10.1016/j.ijhydene.2013.05.071 
[17] Kunce I, Polanski M, Bystrzycki J. Microstructure and hydrogen storage properties of a TiZrNbMoV high entropy alloy synthesized using Laser Engineered Net Shaping (LENS). International Journal of Hydrogen Energy, 39 (2014) 9904-9910. http://dx.doi.org/10.1016/j.ijhydene.2014.02.067

[18] Kunce I, Polanski M, Czujko T. Microstructures and hydrogen storage properties of La-Ni-Fe-V-Mn alloys. International Journal of Hydrogen Energy, 42 (44) (2017) 2715427164. https://doi.org/10.1016/j.ijhydene.2017.09.039

[19] Zepon G, Leiva DR, Strozi RB, Bedoch A, Figueroa SJA, Ishikawa TT, Botta WJ. Hydrogen-induced phase transition of MgZrTiFe0.5Co0.5Ni0.5high entropy alloy, Int. J. Hydrogen Energy. 43 (2018) 1702-1708. https://doi.org/10.1016/j.ijhydene.2017.11.106 [20] De Marco MO, Li Y, Li H-W, Edalati K, Floriano R. Mechanical Synthesis and Hydrogen Storage Characterization of $\mathrm{MgVCr}$ and $\mathrm{MgVTiCrFe}$ High-Entropy Alloy. Advanced Engineering Materials $22 \quad$ (2) $\quad$ (2020) 1-9. https://doi.org/10.1002/adem.201901079

[21] Ouyang L, Huang J, Wang H, Liu J, Zhu M. Progress of hydrogen storage alloys for Ni-MH rechargeable power batteries in electric vehicles: A review. Materials Chemistry and Physics 200 (2017) 164-178. http://dx.doi.org/10.1016/j.matchemphys.2017.07.002 [22] Guo S, Ng C, Lu J, Liu CT. Effect of valence electron concentration on stability of fcc or bcc phase in high entropy alloys. Journal of Applied Physics. 109 (2011) 103505. https://doi.org/10.1063/1.3587228

[23] Zhao X, Ma L, Gao Y, Ding Y, Shen X. Effect of surface treatments on microstructure and electrochemical properties of $\mathrm{La}-\mathrm{Ni}-\mathrm{Al}$ hydrogen storage alloy, International Journal of Hydrogen Energy, Volume 34, Issue 4 (2009) 1904-1909. https://doi.org/10.1016/j.ijhydene.2008.12.027

[24] Huang H, Li G, Zhuang S. Electrochemical Hydrogen-Storage Properties of La0.78Mg0.22Ni2.67Mn0.11Al0.11Co0.52-M1Ni3.5Co0.6Mn0.4Al0.5 Composites. J. Braz. Chem. Soc., Vol. 24, No. 8 (2013) 1339-1344. http://dx.doi.org/10.5935/01035053.20130169

[25] Liang F, Lin J, Wu Y, Wang L. Enhanced electrochemical hydrogen storage performance of $\mathrm{Ti}-\mathrm{V}-\mathrm{Ni}$ composite employing NaAlH4. International Journal of Hydrogen Energy Volume 42, Issue 21 (2017) 14633-14640. https://doi.org/10.1016/j.ijhydene.2017.04.202

[26] Wang L, Young K, Meng T, Ouchi T, Yasuoka S. Partial substitution of cobalt for nickel in mixed rare earth metal based superlattice hydrogen absorbing alloy e Part 1 
structural, hydrogen storage and electrochemical properties. Journal of Alloys and Compounds 660 (2016) 407-415. http://dx.doi.org/10.1016/j.jallcom.2015.11.134

[27] Lv W, Yuan J, Zhang B, Wu Y. Influence of the substitution Ce for La on structural and electrochemical characteristics of La0.75-xCexMg0.25Ni3Co0.5 (x⿺𠃊1/40, 0.05, 0.1, 0.15, 0.2 at. \%) hydrogen storage alloys. Journal of Alloys and Compounds 730 (2018) 360-368. https://doi.org/10.1016/j.jallcom.2017.09.300

[28] Lima GF, Jorge Jr AM, Leiva DR, Kiminami CS, Bolfarini C, Botta WJ. Severe plastic deformation of Mg-Fe powders to produce bulk hydrides J. Phys.: Conf. Ser. 144 (2009) 012015. https://doi.org/10.1088/1742-6596/144/1/012015

[29] Lima GF, Peres MM, Garroni S, Baró MD, Surinyach S, Kiminami CS, Ishikawa TT, Botta WJ, Jorge Jr AM. Microstructural characterization and hydrogenation study of extruded MgFe alloy. Journal of Alloys and Compounds 504 (2010) S299-S301. https://doi.org/10.1016/j.jallcom.2010.03.101

[30] Lima GF, Leiva DR, Ishikawa TT, Bolfarini C, Kiminami CS, Botta WJ, Jorge Jr AM. Hydrogen Sorption Properties of the Complex Hydride $\mathrm{Mg}_{2} \mathrm{FeH}_{6}$ Consolidated by HPT. Materials Science Forum 667-669 (2010) 1053-1058. https://doi.org/10.4028/www.scientific.net/MSF.667-669.1053

[31] Lima GF, Garroni S, Baró MD, Surinyach S, Kiminami CS, Ishikawa TT, Botta WJ, Peres MM, Jorge Jr AM. 2Mg-Fe alloys processed by hot-extrusion: Influence of processing temperature and the presence of $\mathrm{MgO}$ and $\mathrm{MgH}_{2}$ on hydrogenation sorption properties. Journal of Alloys and Compounds 509 (2011) S460-S463. https://doi.org/10.1016/j.jallcom.2010.11.034

[32] Lima GF, Peres MM, Garroni S, Baró MD, Surinyach S, Kiminami CS, Bolfarini C, Botta WJ, Jorge Jr AM. 2Mg-Fe Alloy Processed by Hot Extrusion: Influence of Particle Size and Extrusion Reduction Ratio on Hydrogenation Properties. Materials Science Forum 691 (2011) 3-9. https://doi.org/10.4028/www.scientific.net/MSF.691.3

[33] Lima GF, Triques MRM, Kiminami CS, Botta WJ, Jorge Jr AM. Hydrogen storage properties of $2 \mathrm{Mg}-\mathrm{Fe}$ after the combined processes of hot extrusion and cold rolling. Journal of Alloys and Compounds $586 \quad$ (2014) S409-S412. https://doi.org/10.1016/j.jallcom.2013.01.115

[34] Lima GF, Triques MRM, Kiminami CS, Botta WJ, Jorge Jr AM. Hydrogen storage properties of pure Mg after the combined processes of ECAP and cold-rolling. Journal of $\begin{array}{llll}\text { Alloys and } \quad \text { Compounds } & 586 \quad \text { (2014) } & \text { S405-S408. }\end{array}$ https://doi.org/10.1016/j.jallcom.2013.03.106 
[35] Silva RA, Leal Neto RM, Leiva DR, Ishikawa TT, Kiminami CS, Jorge Jr AM, Botta WJ. Room temperature hydrogen absorption by $\mathrm{Mg}$ and $\mathrm{Mg}$-TiFe nanocomposites processed by high-energy ball milling. International Journal of Hydrogen Energy 43 (27) (2018) 12251-12259. https://doi.org/10.1016/j.ijhydene.2018.04.174

[36] Andreani GFL, Triques MRM, Leiva DR, Roche V, Cardoso KR, Ishikawa TT, Botta WJ, Jorge Jr AM. Hydrogen storage properties of $2 \mathrm{Mg}-\mathrm{Fe}$ mixtures processed by hot extrusion: Effect of ram speeds. International Journal of Hydrogen Energy 44 (36) (2019) 20203-20212. https://doi.org/10.1016/j.ijhydene.2019.06.039

[37] Chow J, Kopp RJ, Portney PR. Energy resources and global development. Science 302 (2003) 1528-1531. https://doi.org/10.1126/science.1091939

[38] Davis SJ, Caldeira K, Matthews HD. Future $\mathrm{CO}_{2}$ emissions and climate change existing energy infrastructure, Science $329 \quad$ (2010) 1330-1333. https://doi.org/10.1126/science.1188566

[39] Eftekhari A, Fang B. Electrochemical hydrogen storage: Opportunities for fuel storage, batteries, fuel cells, and supercapacitors. International Journal of Hydrogen Energy 42 (40) (2017) 25143-25165. https://doi.org/10.1016/j.ijhydene.2017.08.103

[40] Popov BN, Zheng G, White RE. Determination of transport and electrochemical kinetic parameters of M-H electrodes. J Appl Electrochem 26 (1996) 603-611. https://doi.org/10.1007/BF00253458

[41] Kleperis J, Wójcik G, Czerwinski A, Skowronski J, Kopczyk M, BeltowskaBrzezinska M. Electrochemical behavior of metal hydrides. J Solid State Electrochem 5 (2001) 229-249. https://doi.org/10.1007/s100080000149

[42] Kuriyama N, Sakai T, Miyamura H, Uehara I, Ishikawa H, Ikeda M, Iwasaki T, Electrochemical impedance and deterioration behavior of metal hydride electrodes, Journal of Alloys and Compounds, 202 (1993) 183-197. https://doi.org/10.1016/09258388(93)90538-X

[43] Kalisvaart WP, Niessen RAH, Notten PHL, Electrochemical hydrogen storage in MgSc alloys: A comparative study between thin films and bulk materials, Journal of Alloys and Compounds $417 \quad$ 280-291. https://doi.org/doi:10.1016/j.jallcom.2005.09.042

[44] Hu F, Li YZ, Xu JY, Zhang GF, Liu ZC, Zhang YH. Studying of electrochemical discharging and kinetic properties of Ni-TiF3-CeMg12 composite materials with nanocrystalline and amorphous structure, Applied Surface Science 447 (2018) 15-21. https://doi.org/10.1016/j.apsusc.2018.03.192 
[45] Tliha M, Khaldi C, Boussami S, Fenineche N, El-Kedim O, Mathlouthi H, Lamloumi J. Kinetic and thermodynamic studies of hydrogen storage alloys as negative electrode materials for Ni/MH batteries: a review, J. Solid State Electrochem 18 (2014) 577-593. https://doi.org/10.1007/s10008-013-2300-3

[46] Liu YF, Pan HG, Gao MX, Wang QD, Advanced hydrogen storage alloys for Ni/MH rechargeable batteries, J. Mater. Chem. $21 \quad$ (2011) 4743-4755. https://doi.org/10.1039/C0JM01921F

[47] Liu YF, Pan HG, Gao MX, Li R, Sun XZ, Lei YQ. Investigation on the characteristics of $\mathrm{La} 0.7 \mathrm{Mg} 0.3 \mathrm{Ni} 2.65 \mathrm{Mn} 0.1 \mathrm{Co} 0.75+\mathrm{x}(\mathrm{x}=0.00-0.85)$ metal hydride electrode alloys for Ni/MH batteries Part II: electrochemical performances, J. Alloys Compd. 388 (2005) 109-117. https://doi.org/10.1016/j.jallcom.2004.07.014

[48] Anik M. Electrochemical hydrogen storage capacities of Mg2Ni and MgNi alloys synthesized by mechanical alloying. J Alloys Comp 491 (2010) 565-570. https://doi.org/10.1016/j.jallcom.2009.11.004

[49] Anik M, Akay I, O” Zdemir G, Baksan B. Electrochemical hydrogen storage performance of Mg-Ti-Zr-Ni alloys. Int J Hydrogen Energy 34 (2009) 9765-9772. https://doi.org/10.1016/j.ijhydene.2009.10.036

[50] Zheng G, Popov BN, White RE. Electrochemical determination of the diffusioncoefficient of hydrogen through an LaNi4.25Al0.75 electrode in alkaline aqueous solution. Journal of the Electrochemical Society 142 (8) (1995) 2695-2698. http://dx.doi.org/10.1149/1.2050076 